\section{RESENHA}

Recebido em: 25/02/2017

Aceito em: 04/07/2017

\title{
Serviços de documentação audiovisual em televisão: uma linha tênue entre Espanha e Brasil
}

\author{
Francisco Edvander Pires SANTOS (edvanderpires@gmail.com)* \\ * Bibliotecário da Biblioteca de Ciências Humanas e Mestrando do Programa de Pós-Graduação em \\ Ciência da Informação - UFC.
}

\section{CALDERA-SERRANO, Jorge; ARRANZ-ESCACHA, Pilar. Documentación audiovisual} en televisión. Barcelona: Editorial UOC, 2013. Livro eletrônico: Kindle e-reader.

Jorge Caldera-Serrano é professor titular na Facultad de Ciencias de la Documentación y la Comunicación da Universidad de Extremadura e pode ser considerado referência na Espanha quando o assunto é a gestão da informação audiovisual, sob o viés dos serviços de documentação, mais especificamente na área televisiva. São muitas as suas publicações que versam sobre essa temática e que se destinam tanto ao leitor que está iniciando suas pesquisas acerca do tratamento da documentação audiovisual quanto aos pesquisadores que já trabalham com o tema de longa data. Na obra Documentación audiovisual en televisión (2013), ele divide a autoria com Pilar Arranz-Escacha, pesquisadora que também contribuiu com estudos nessa área.

Se a contribuição de ambos diz respeito à realidade espanhola, por que trazê-los para a discussão do tema à brasileira? Respondo: muitas são as aproximações entre a prática na gestão da informação audiovisual televisiva na Espanha com a prática nos centros de documentação do Brasil, porém, com a diferença de que ainda permanece uma certa lacuna no campo teórico da Ciência da Informação do lado verde-amarelo. E é tendo em vista essas aproximações e diferenças que a leitura desta obra é recomendada, sendo um verdadeiro "guia" teórico-prático para aqueles que desejam adentrar ou que já enveredaram pelo caminho do audiovisual enquanto pesquisadores e/ou gestores de informação.

Já na introdução do livro, os autores chamam a atenção para um fato bastante verídico: se uma emissora de TV almeja se tornar a 'melhor', a gestão de seu acervo audiovisual deve acompanhar o seu ritmo e a produção de seu conteúdo. Dessa forma, os autores conduzem o leitor a uma reflexão a partir da seguinte questão:

\begin{abstract}
A gestão da documentação audiovisual nas emissoras de TV é também garantia da preservação do acervo cultural audiovisual, um patrimônio tão importante quanto o bibliográfico e o arquivístico, já que, por meio das imagens, podemos determinar como fomos no passado e no que nos tornamos [no presente]. Nesse sentido, a preservação do material audiovisual é um dever não apenas das emissoras de televisão, mas também deveria ser garantido pelo Estado. ([p. 8-9], paginação e tradução nossa).
\end{abstract}

\section{v. 22, n. $50,2017$. p. $241-245$ ISSN 1518-2924 \\ BIB⿺辶卬}


No primeiro capítulo, intitulado A televisão e a Documentação, os autores retratam um breve histórico de como a humanidade chegou até a TV, expondo a necessidade do homem em reproduzir em imagens aquilo que o rodeava. Partindo, então, das necessidades de informação das empresas televisivas, a comunidade constituída especificamente por jornalistas exige respostas dos sistemas documentais, ou seja, do centro de documentação que se constitui nas emissoras de TV. Diante disso, os autores contextualizam o porquê dos serviços de documentação em TV, exemplificando com base no que ocorre frequentemente na rotina dos ambientes de televisão (tanto na Espanha quanto em outros países): se um determinado usuário solicita imagens de pinguins em seu habitat natural, existem duas opções para obtê-las: "a primeira seria viajar com toda a equipe de produção para o Polo, gravar os pinguins e retornar ao local a cada vez que necessitarem de imagens; a segunda seria viajar, gravar uma única vez, arquivar as imagens e recuperá-las tantas vezes forem necessárias [...]" ([p. 17-18], paginação e tradução nossa). Baseados nessa segunda possibilidade, os autores defendem que manter um serviço de documentação numa emissora de TV poderá reduzir custos de produção, além de preservar permanentemente o material audiovisual da emissora e, consequentemente, o patrimônio local e/ou estatal.

Discorrendo acerca dos serviços de documentação, Caldera-Serrano e Arranz-Escacha citam, tendo como base exemplos reais, que esses serviços podem estar subordinados a diferentes departamentos, que variam de acordo com o organograma de cada empresa televisiva, dentre eles: Direção de Produção, de Programação, de Operações, de Gerência e Comerciais, de Jornalismo etc. Essa estrutura organizacional não difere da brasileira; pelo contrário, sua semelhança possibilita o alcance de um padrão na rotina de trabalho das emissoras de TV. Assim, conforme o departamento ao qual o serviço de documentação esteja subordinado, a sua estrutura interna (setorização) também poderá variar. Com base em pesquisadores da área, os autores exemplificam quatro tipos de estrutura: por tipo de atividade (que divide o serviço em dois setores: videoteca, responsável pelo preparo das mídias para gravações e pelo empréstimo das mídias arquivadas, e centro de documentação, responsável pela tomada de decisões gerenciais e representação da informação); por tipo de fundo documental (que divide e integra num único sistema os diferentes tipos de mídia: audiovisual, fotográfica, sonora e escrita); por tipo de programas (que define o organograma segundo as produções da emissora, dividindo-as em duas centrais: uma de entretenimento e outra de jornalismo, as quais se subdividem de acordo com o tipo de fundo documental, realidade semelhante à do Brasil); e por especialização de temática e de técnicas documentais (dividido, basicamente, em dois setores: o de representação da informação e o de atendimento ao usuário).

Dentre essas opções, os autores enfatizaram o organograma televisivo definido pelo tipo de fundo documental, "já que esta estrutura permite identificar claramente os diferentes suportes e tipos de documentos que podem ser encontrados nos centros [de documentação]" ([p. 19], paginação e tradução nossa). Nesse sentido, são descritos os tipos de documentos que compõem o acervo de uma emissora de TV: documentação audiovisual, escrita, sonora e fotográfica, tendo, obviamente, a informação audiovisual como carro-chefe e discussão central desta obra. Apesar disso, os autores trazem o conceito de documentação escrita, inserindo-a na composição dos serviços oferecidos pela biblioteca ou hemeroteca de uma empresa televisiva. Seria um serviço complementar para o embasamento das reportagens e das pesquisas mais aprofundadas para as pautas, ou mesmo para a equipe técnica se especializar sobre um determinado assunto de sua competência, e os autores vão mais além na discussão, reforçando a importância de um legítimo 
serviço de referência nesses ambientes, destacando que, além de livros, jornais e revistas, o acervo seja formado por dicionários, guias, diretórios, anuários, biografias, obras raras, clippings, bibliografias, bases de dados de agências de notícias, legislação, jurisprudência, dentre outras fontes de informação.

Citando a fonoteca (termo usado pelos autores como sinônimo de "biblioteca de sons", composta pela documentação sonora proveniente do rádio), os autores constatam a integração entre as mídias (rádio e TV) e afirmam que "a missão das unidades de documentação sonora é fornecer informação para a elaboração da programação da emissora e compor o acervo histórico sonoro da emissora e, por extensão, do nosso país e do mundo." ([p.23], paginação e tradução nossa). Acerca da documentação fotográfica, cujo ambiente é denominado pelos autores de fototeca, eles afirmam que é, provavelmente, a menos utilizada no organograma de uma empresa audiovisual, sendo utilizada apenas para "cobrir" uma possível ausência de imagens em movimento e, ainda assim, sob a resistência de alguns editores. Assim, tem-se contextualizado um verdadeiro ambiente de banco de dados nas emissoras de televisão, onde texto, fotografia, som e, principalmente, imagens em movimento se integram para se produzirem conteúdos de qualidade, o que exige uma gestão eficaz de todo esse universo informacional produzido e consumido. No Brasil, vê-se essa realidade em grandes grupos de comunicação, principalmente com a chamada convergência dos meios de comunicação, entendida como sendo a integração entre os diferentes tipos de mídia.

Após essa contextualização, os autores retornam ao ponto central do livro e iniciam a discussão sobre os conceitos, as funções e o valor da documentação audiovisual. Inicialmente, ressaltam as duas correntes teóricas acerca desse universo: uma que divide a gestão unicamente de imagens, de áudio e, em seguida, da união de ambos; e outra que engloba o audiovisual com todos os seus elementos, e é com base nesta última corrente que se dá a explanação no decorrer da obra. No que se refere à conceituação, são citadas quatro publicações, que convergem para uma mesma definição sobre documentação audiovisual: aquela que contém imagens em movimento e sons sincronizados. Quanto às funções, os autores elencam três finalidades principais: gerir a documentação produzida pela emissora de TV, disponibilizá-la aos usuários internos e externos e salvaguardá-la enquanto patrimônio institucional, histórico e cultural de um país.

Caldera-Serrano e Arranz-Escacha caracterizam a produção audiovisual partindo da tipologia documental nos ambientes de televisão, dividindo-a segundo a entidade produtora dos documentos, bem como aquela que detém os direitos de imagem sobre eles, que contempla os documentos próprios e externos; e conforme o grau de produção da informação, que gera os documentos primários, secundários e terciários. Os documentos próprios são definidos como aqueles produzidos pela própria emissora, a partir de conteúdo próprio, dentre telejornais, reportagens, cobertura de eventos, programas de entretenimento etc., enquanto que os externos provêm de agências de notícias, produtoras independentes, profissionais free lance ou emissoras afiliadas. Classificam-se como documentos primários aqueles que são gerados a partir de imagens brutas (aquelas que chegam da rua e não passam por edição) e/ou de exibição ao vivo. Os secundários trazem imagens que passaram por edição, gravações de off (narração de um repórter "em cima" de uma imagem, por exemplo), montagem ou pós-produção, e que, somente após esses processos, foram veiculadas pela emissora. Os documentos terciários são definidos pelos autores como sendo as "imagens de arquivo", ou seja, aquelas já existentes na TV e que estão sendo (re)utilizadas mediante solicitação prévia ao serviço de documentação da emissora, visando compor um novo material audiovisual a ser incorporado ao acervo, como uma reportagem, por exemplo. Essa 
realidade é vivenciada cotidianamente nas emissoras de televisão brasileiras, cuja variedade e produção documental crescem numa velocidade cada vez maior.

0 valor da documentação audiovisual é discutido a partir de uma dupla dimensão: valor de exploração e valor patrimonial. Sobre o primeiro, os autores ressaltam a reutilização de imagens para a composição de um novo material audiovisual, como já mencionado anteriormente, o que gera economia para a emissora no que tange aos gastos com equipes de gravação em lugares longínquos, além da possibilidade de comercialização das imagens produzidas pela TV, gerando receita para algumas emissoras. No que se refere ao segundo valor, entra em discussão o caráter histórico dos documentos audiovisuais, reforçando a ideia de preservação do patrimônio audiovisual, tanto para a instituição quanto para a sociedade. Nesse contexto, os autores chamam a atenção para o fato de não haver, na Espanha, nenhuma instituição que assuma a responsabilidade pela salvaguarda de todo o material (patrimônio) televisivo produzido no país, ao contrário do que ocorre, segundo eles, com o patrimônio audiovisual cinematográfico (na Espanha) e do que ocorre com a preservação de imagens de TV em países como a França. Quanto a isso, têm-se no Brasil TVs clipping, de caráter privado, em diversos estados brasileiros, que se responsabilizam por gravar toda a programação das emissoras visando salvaguardar as imagens, mas nem sempre permanentemente, e disponibilizá-las para clientes em potencial, mediante a comercialização.

Após essa análise, os autores passam a discutir as características da documentação audiovisual em telejornais, levando em consideração aspectos referentes à: natureza da informação jornalística; falta de normalização do tratamento documental, apesar de haver diretrizes respaldadas pela Federación Internacional de Archivos de Televisión (FIAT/IFTA); organicidade do material; perspectiva do usuário; unidade documental (serviço de documentação); análise do conteúdo (indexação); dificuldade na seleção de material; "modas" jornalísticas, ou seja, as mudanças frequentes na exigência dos usuários do serviço de documentação televisivo; variedade de contextos de uso das imagens gravadas; rapidez de respostas, tendo em vista a urgência com que os usuários necessitam das imagens; dicotomia áudio-vídeo, na qual o áudio assume potencial informativo na análise da imagem; instrumentos de análise documental pouco desenvolvidos, e nesse ponto os autores trazem uma importante reflexão acerca do uso das linguagens documentárias e da análise facetada (Ranganathan) na representação da informação televisiva.

Abordando a mudança de paradigma nas emissoras de televisão, mais especificamente do formato analógico (suporte físico) para o digital, é contextualizado o cenário da informação audiovisual em caráter digital, reforçando a necessidade de haver novos métodos de trabalho e novos perfis profissionais (realidade não muito distante da brasileira). Nesse sentido, é traçado na obra um comparativo da rotina de trabalho antes e depois do formato digital, com destaque para os suportes utilizados na gravação e disponibilização das imagens. Complementando esse ponto, há uma descrição do workflow no ambiente de uma emissora de TV, desde a concepção da pauta na redação à (re)utilização das imagens em novos materiais audiovisuais. Em seguida, são apresentadas as consequências desse processo de digitalização da práxis televisiva e, consequentemente, documental, com destaque para a substituição das mídias físicas pelos discos rígidos, e dos usuários que delegam a busca pelos usuários (agora interagentes) em rede, que acessam as imagens compartilhadas em meio digital. Além disso, também são mencionados: a tecnologia streaming, a alta qualidade de imagem, o autoarquivamento, a rapidez na seleção do que será arquivado permanentemente, o compartilhamento das imagens em tempo real e a convergência dos veículos/canais 
de comunicação, ao lançar mão da comercialização, da Web, dos dispositivos móveis e de outras tecnologias.

Os autores abordam ainda os critérios de seleção das imagens, assim como a preservação e conservação em meio digital, atentando para a importância da elaboração de políticas de seleção e de arquivamento. Passando para a análise das imagens em movimento, delineiam-se fases e conceitos para a análise documental, tais como: descrição (física e de conteúdo), indexação, decupagem, controle terminológico e unidade documental. Nesse sentido, são apresentados exemplos e diretrizes para a gestão da informação audiovisual em bases de dados, com metadados constituídos a partir da definição de áreas que refletem as características do audiovisual televisivo. Por fim, a obra traz uma reflexão acerca da difusão interna e externa da documentação televisiva, ou seja, sob o ponto de vista do usuário interno e externo, reforçando a necessidade da existência de um acervo de imagens em ambiente digital.

A realidade descrita pelos autores não difere muito da realidade brasileira no que tange à documentação audiovisual em emissoras de TV. O livro traz um rico aporte teórico referente ao universo da informação e documentação audiovisual e apresenta a contextualização de todo o ambiente de informação televisiva, ou seja, a gestão da informação em televisão na teoria e na prática. É uma obra ideal para quem deseja se aprofundar na literatura acerca dessa temática, bem como entender e trabalhar com a gestão de ambientes de informação ou serviços de documentação televisiva. 